\title{
VARIÁVEIS LIMNOLÓGICAS NO CORREDOR FLUVIAL DO RIO PARAGUAI, ENTRE A BAÍA DO PONTO CERTO A FOZ DO CÓRREGO JACOBINA, CÁCERES - MATO GROSSO
}

Thales Ernildo de Lima ${ }^{(a)}$,Célia Alves de Souza ${ }^{(b)}$, Cristiane da Silva Lima ${ }^{(c)}$, Carolina da Costa Tavares $^{(d)}$

(a) Departamento de Geografia/Universidade do Estado de Mato Grosso:lima.thales@outlook.com

${ }^{(b)}$ Departamento de Geografia/Universidade do Estado de MatoGrosso: celiaalvesgeo@globo.com

${ }^{\text {(c) }}$ Departamento de Geografia/Universidade do Estado de Mato Grosso: cristiane-silva89@ @otmail.com

${ }^{\text {(d) Departamento de Geografia/Universidade do Estado de Mato Grosso: carolina tavares 5@ @otmail.com }}$

\section{EIXO: BACIAS HIDROGRÁFICAS E RECURSOS HÍDRICOS: ANÁLISE, PLANEJAMENTO EEGESTÃO}

\begin{abstract}
Resumo
O presente trabalho tem por objetivo analisar variáveis limnológicas da água, no rio Paraguai no trecho entre o Ponto Certo a foz da Jacobina, Cáceres - Mato Grosso. A área de estudo está localizada entre a baía do Ponto Certo à foz do córrego Jacobina, no corredor fluvial do rio Paraguai com de 13,63 km de extensão. As amostras de água foram coletadas em quatro pontos ao longo da área de estudo no período de seca (setembro) de 2015. Para a coleta das amostras de água foram utilizados frascos devidamente esterilizados, etiquetados e preparados com reagentes químicos recomendados a cada parâmetro, disponibilizados pelo laboratório de análises físicoquímicas e bacteriológicas da água, Analítica ciência e tecnologia. As variáveis $\mathrm{pH}$, oxigênio dissolvido, saturação de oxigênio dissolvido, temperatura e condutividade elétrica foram levantados através da sonda multiparamétrica (marca Hach, modelo HQ40d). A temperatura da água variou entre as seções de $29,05^{\circ} \mathrm{C}$ a $29,2^{\circ} \mathrm{C}$. A condutividade elétrica variou entre $(36,8$ $\mu \mathrm{s} / \mathrm{cm}$ a $38,1 \mu \mathrm{s} / \mathrm{cm})$. O oxigênio dissolvido identificado na área de estudo apresentou variação de (6,54 mg. $\mathrm{L}^{-1}$ a $\left.6,57 \mathrm{mg} \cdot \mathrm{L}^{-1}\right)$. A caracterização ácida dos ambientes aquáticos variou em básico $(7,09)$ a ácido $(6,38)$.
\end{abstract}

Palavras Chaves: Qualidade da água; Rio Paraguai; Varáveis Limnológicas.

\section{INTRODUÇÃ̃o}

Rios são definidos como um amplo corpo de água em movimento, limitado a um canal, geralmente este termo é usado para indicar o principal tronco do sistema de drenagem (CUNHA; GUERRA, 2010).

O rio Paraguai é um dos principais rios de planície do Brasil, possui suas nascentes localizadas em área de planalto (SOUZA, SOARES e SILVA, 2008), que por sua vez sofre com a intensificação da agricultura mecanizada, fato este consumado através do desmatamento, originando problemas tais como, assoreamento e entrada de poluentes nos corpos d'água (CASARIN \& SANTOS, 2005).

A água indispensável à vida humana tem utilização variável, sendo aplicada à irrigação, recreação, turismo, entre outros (TUNDISI, 2003). O despejo de poluentes e resíduos humanos são em sua maioria os causadores de doenças (TUNDISI; MATSUMURA TUNDISI, 2011). Portanto a qualidade 
OS DESAFIOS DA GEOGRAFIA FÍSICA NA FRONTEIRA DO CONHECIMENTO

Instituto de Geociências - Unicamp

Campinas - SP

28 de Junho à 02 de Jutho de 2017

da água é um fator que gera benefícios ao manejo dos corpos hídricos no geral e a sociedade, realidade relacionada à incidência de doenças, em especial a diarreia (QUEIROZ, HELLER, SILVA, 2009).

A literatura mostra a compreensão dos estudos sobre a forma de organização dos ambientes aquáticos, aspectos estes: físicos, químicos e biológicos sobre os sistemas de água doce (limnologia) (CALLHEIROS e FERREIRA, 1996).

FERNANDEZ (1995) salienta que a dinâmica fluvial altera os parâmetros de qualidade de água, a erosão fluvial introduz sedimentos no sistema os constituintes de menor granulometria são colocados em suspensão aumentando a turbidez que interferem na quantidade de luz que penetra a coluna de água, modificando a fotossíntese das plantas.

O presente trabalho tem por objetivo analisarvariáveislimnológicas da água, no rio Paraguai no trecho entre o Ponto Certo a foz da Jacobina, Cáceres - Mato Grosso.

\section{MATERIAL E MÉTODOS}

A área de estudo está localizada entre a baía do Ponto Certo à foz do córrego Jacobina, no corredor fluvial do rio Paraguai, encontra-se entre as coordenadas geográficas $16^{\circ} 13^{\prime} 31.60^{\prime \prime}$ a $16^{\circ} 17^{\prime} 8.25^{\prime \prime}$ Latitude Sul e 5744'52.27" a 5746'21.65" Longitude Oeste. Com de 13,63 km de extensão.

As amostras de água foram coletadas em quatro pontos ao longo da área de estudo no período de seca (setembro) de 2015. Para a coleta das amostras de água foram utilizados frascos devidamente esterilizados, etiquetados e preparados com reagentes químicos recomendados a cada parâmetro, disponibilizados pelo laboratório de análises físico-químicas e bacteriológicas da água, Analítica ciência e tecnologia, localizado na rua quatro, casa 14, bairro são José, Cuiabá - Mato Grosso/BR.

As variáveis temperatura, condutividade elétrica, oxigênio dissolvido e pH foram levantados através da sonda multiparamétrica (marca Hach, modelo HQ40d).

\section{RESULTADOS E DISCUSSÃO}

$\mathrm{Na}$ área de estudo, em 2014 a quantidade de sedimento em suspensão variou de 260 a $360 \mathrm{mg} / \mathrm{l}$, ainda no mesmo ano foi constado feições morfológicas positivas e negativas como baías, lagoas, ilhas, barras de sedimento, e canal comaltado (LIMA, et al, 2014).

Temperatura - A temperatura representa o grau de energia cinética das moléculas e a velocidade das reações químicas diretamente proporcionais, ou seja, quanto maior a temperatura de um ambiente, mais rápidas serão as reações químicas que ocorrerão neste sistema (BÜHLER, 2016). 
XVIII Simpósio Brasileiro

de Geografia Fisica Aplicada

I Congresso Nacional

de Geografia Física
OS DESAFIOS DA GEOGRAFIA FISICA NA FRONTEIRA DO CONHECIMENTO

Instituto de Geociências - Unicamp

Campinas - SP

28 de Junho à 02 de Julho de 2017

A temperatura média das seções seguiram os seguintes valores: seção $01\left(29,05^{\circ} \mathrm{C}\right)$, seção 02 $\left(29,2^{\circ} \mathrm{C}\right)$, seção $03\left(29,1^{\circ} \mathrm{C}\right)$ e seção $04\left(29,05^{\circ} \mathrm{C}\right)$. Valores estes obtidos com a coleta da amostra em aproximadamente $20 \mathrm{~cm}$ da coluna d'água.

Condutividade Elétrica - Condutividade elétrica é a aptidão da água de transmitir corrente elétrica em função da dissolução de ânions e cátions, principalmente ferro e manganês, mas também de potássio, cloretos, sódio, cálcio e magnésio (LIBÂNEO, 2010).

Segundo Bühler (2016) não a legislação vigente que limite padrões aceitáveis de condutividade elétrica, no entanto este parâmetro é um importante indicador de íons dissolvidos na água, especialmente aqueles provindos do material rochoso da bacia.

Foram obtidos valores para seção $01(36,8 \mu \mathrm{s} / \mathrm{cm})$, seção $02(37,1 \mu \mathrm{s} / \mathrm{cm})$, seção $03(37,6 \mu \mathrm{s} / \mathrm{cm})$ e Seção $04(38,1 \mu \mathrm{s} / \mathrm{cm})$.

Ao comparar com a pesquisa de Bühler (2016), onde a mesma obteve valores entre $(118,08 \mu \mathrm{s} / \mathrm{cm}$ a $337,26 \mu \mathrm{s} / \mathrm{cm}$ ), nota-se que os valores obtidos estão muito abaixo, isto pode ser justificado pela ausência de atividade antrópica, tais como esgotos ou plantações ao entorno, pois nesse trecho as condições ambientais são de preservação.

Oxigênio Dissolvido - Entre as caracterizações dos ambientes aquáticos, Esteves (1998) caracteriza o oxigênio dissolvido (OD) como uma das variáveis mais importantes, pois sua escassez pode beneficiar a liberação de compostos tóxicos na água por determinados processos biológicos.Marottaet al., (2008) expõe exemplo deliberação de gases derivado da degradação da matéria orgânica por colônias de bactérias.

Os valores identificados nas seções $01\left(6,55 \mathrm{mg} \cdot \mathrm{L}^{-1}\right), 02\left(6,54 \mathrm{mg} \cdot \mathrm{L}^{-1}\right), 03\left(6,51 \mathrm{mg} \cdot \mathrm{L}^{-1}\right)$ e $04(6,57$ mg. $\left.L^{-1}\right)$, estão acima do que determinada a Resolução 357/05 do CONAMA, que determina na legislação que o valor não pode estar inferior a $5 \mathrm{mg} / \mathrm{L}$. Macedo et al.; (2015) realizou estudos sobre as causas do fenômeno ocorrido em varias regiões do Brasil intitulada "dequada", onde a mortandade de peixes esta relacionada a taxas de oxigênio inferiores a $3 \mathrm{mg} . \mathrm{L}^{-1}$.

pH - O potencial hidrogeniônico $(\mathrm{pH})$ das águas representa características ácidas ou alcalinas (básicas) da água através da concentração de íons H+ presentes no sistema. Sua escala apresenta variação entre 0 a 14 , sendo o $\mathrm{pH}=7$ considerado - "neutro"; inferior a 7 considerado - "ácido" e superior a 7 considerado - "básico".

A seção 01 caracterizou-se como ligeiramente básico $(7,09)$, enquanto as demais como ligeiramente ácidas (seção $02(6,82)$, seção $03(6,83)$ e seção $04(6,38)$ ). Libâneo (2010) afirma que as condições ideais para a manutenção da vida aquática em águas naturais de superfície, o pH tem que estar entre 
6,0 e 8,5, no entanto a resolução 357/05 do CONAMA preconiza que águas doces de classe II $^{1}$ devem manter o pH entre 6,0 e 9,0 .

\section{CONCLUSÃO}

A temperatura da água constatada entre a baía do Ponto Certo a Foz do córrego Jacobina variou entre as seções de $29,05^{\circ} \mathrm{C}$ a $29,2^{\circ} \mathrm{C}$.

A condutividade elétrica variou entre $(36,8 \mu \mathrm{s} / \mathrm{cm}$ a $38,1 \mu \mathrm{s} / \mathrm{cm})$ valores relativamente baixos comparados a outros trabalhos realizados no rio Paraguai no período da seca, pois a tendência é agrupação dos íons para este período. Os mesmos valores justificam-se pela ausência de atividade antrópica, tais como esgotos ou plantações ao entorno.

Estudos apontam o (OD) como uma das variáveis mais importantes, pois a preocupação relativa aos ambientes aquáticos e a manutenção da biodiversidade para os mesmos. O oxigênio dissolvido identificado na área de estudo apresentou variação de $\left(6,54 \mathrm{mg} \cdot \mathrm{L}^{-1}\right.$ a $\left.6,57 \mathrm{mg} \cdot \mathrm{L}^{-1}\right)$.

A caracterização ácida dos ambientes aquáticos variou em ligeiramente básico $(7,09)$, enquanto as demais como ligeiramente ácidas $(6,38$ a 6,83$)$.

\section{REFERÊNCIAS BIBLIOGRÁFICAS}

BRASIL. Resolução $\mathbf{n}^{\circ}$. 357. Dispõe sobre a classificação dos corpos de água e diretrizes ambientais para o seu enquadramento, bem como estabelece as condições e padrões de lançamento de efluentes, e dá outras providências. Diário Oficial da União de 18 de março de 2005.

BÜHLER, B. F. A influência da geologia e do uso e ocupação da terra na qualidade da água e composição sedimentar do córrego Jacobina, município de Cáceres - MT. 2016. Dissertação (Mestrado em Ciências Ambientais) - Instituto de Ciências Naturais e Tecnológicas, Universidade do Estado de Mato Grosso, Cáceres.

CALHEIROS, D. F.; FERREIRA, C. J. A. Alterações limnológicas no rio Paraguai (“dequada") e o fenômeno natural de mortandade dos peixes no Pantanal Mato-Grossense - MS. Corumbá. MS: EMBRAPA-CPAP, 1996. 51p. (EMBRAPA-CPAP. Boletim de Pesquisa, 7).

CASARIN, R. \& SANTOS, S. Características ambientais na área das nascentes do rio Paraguai. In: (Anais) Simpósio Nacional de Geografia Agrária, 3\& Simpósio Internacional de Geografia Agrária, 2, 2005, Presidente Prudente. Anais... Presidente Prudente: Editora UNESP, 2005, p. 1-10.

CUNHA, S, B; GUERRA, A, J, T (orgs). A questão ambiental: diferentes abordagens - $6^{\mathrm{a}}$ ed. - Rio de Janeiro: Bertrand Brasil, 2010, 250p.

ESTEVES, F. A. Fundamentos de Limnologia. $2^{a}$ Ed. Rio de Janeiro: Interciência, 1998. 602 p.

FERNANDEZ, O. V. Q. Erosão Marginal No Lago UHE Itaipu (PR).Tese Doutorado em Geociências, Geociências e Meio Ambiente. Rio Claro (SP), 1995.

LIBÂNEO, M. Fundamentos de qualidade e tratamento de água.3 Ed. Campinas-SP: Editora Átomo, 2010.

\footnotetext{
${ }^{1}$ CONAMA 357/05 CAP. II. Seção I. § III. classe 2: águas que podem ser destinadas: Ao abastecimento para consumo humano, após tratamento convencional; á recreação de contato primário, tais como natação, esqui aquático e mergulho, À aquicultura e à atividade de pesca; etc.
} 
LIMA, et al, 2014. Feições, Morfologia e Sedimentos de Fundo e Suspensão do Rio Paraguai no Pantanal de Cáceres - Mato Grosso, no trecho entre abaía do Ponto Certo a foz da Jacobina.REVISTA GEONORTE, Edição Especial 4, V.10, N.1, p.391-396, 2014.(ISSN 2237-1419).

MACEDO, H. A.; STEVAUX, J. C.; SILVA, A.; MERINO, E. R.; PUPIM, F. N.; BERGIER, I. Methodology for analysis of distribution and classifacation of the intensity of dequada fish kill events in the Pantanal wetland.Geografia / Associação de Geografia Teorética. Vol. 40, Número especial, agosto 2015. $5^{\circ}$ GeoPantanal. 2015.

MAROTTA, H.; SANTOS, R.O. dos.; PRAST, A.E. Monitoramento limnológico: um instrumento para conservação dos recursos hídricos no planejamento e na gestão urbano-ambientais. Revista Ambiente e Sociedade. Campinas, v. 11, n. 1, p. 207-218, 2008.

QUEIROZ, J.T.M. de.; HELLER, L.; SILVA, S.R. da. Análise da correlação de ocorrência da doença diarreica aguda com a qualidade da água para consumo humano no município de Vitória - ES.Saúde \& Sociedade. São Paulo, v.18, n.3, p.479-489, 2009.

SOUZA, C.A.; SOARES, J.C.O.; SILVA, L.N.P. Pantanal Matogrossense: ocupação da planície e navegação no Rio Paraguai entre a cidade de Cáceres e a Estação Ecológica da Ilha de Taiamã (MT). In: SANTOS, J.E. \& GALBIATI, C. (Orgs.), Gestão e Educação Ambiental: Água, Biodiversidade e Cultura. São Carlos: Editora Rima, p. 1-21, 2008.

TUNDISI, J.G. Água no século XXI: enfrentando a escassez. São Carlos: Rima, 2ed, 2003. 251 p.

TUNDISI, J.G.; MATSUMURA TUNDISI, T. Recursos Hídricos no século XXI. São Paulo, Oficina de Textos, 2011. 328 p. 